\title{
Development of an Analytical Method for the Trace Metallic Assay of (U-Pu-Zr) Alloy Fuel Using the D.C. Arc AES Technique
}

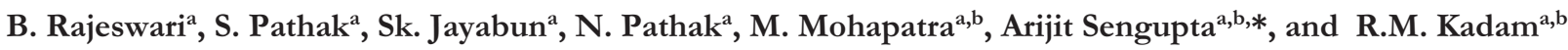 \\ ${ }^{a}$ Radiochemistry Division, Bhabha Atomic Research Centre, Trombay, Mumbai-400085, India \\ ${ }^{\mathrm{b}}$ Homi Bhabha National Institute, Mumbai, India
}

\section{INTRODUCTION}

Chemical quality control and quality assurance are one of the essential steps to be followed in the nuclear fuel cycle in order to achieve the desired performance of the nuclear fuel and associated materials (1-3). Simultaneous multilement atomic emission spectrome try (AES) was used for the present study (4-7). D.C. arc carrier distillation has long been exploited as an analytical tool for trace metal assay (8-10). In this technique, a suitable carrier was used to sweep away metallic analytes into the arc in the form of volatile halide and keeping the major matrix in the electrode as refractory oxides. This selective distillation is desirable in order to avoid spectral interference from the major matrix. The major elements of nuclear materials, such as $\mathrm{U}, \mathrm{Th}$, $\mathrm{Pu}, \mathrm{Zr}$, etc., are multi-electronic systems and have line-rich emission spectra. Therefore, trace level determination of the analytes in such a matrix can lead to erronious results due to spectral overlap (11-14). The carrier distillation technique utilizes the physical separation instead of the chemical separation adopted for liquid samples in inductively coupled plasma atomic emission spectrometry (ICP-AES). This approach not only reduces sample contamination during its processing, but also reduces the individual radiation expossure and overall analysis time. In view of these points, the D.C. arc carrier distillation method is considered as the most convenient analytical tool for trace metal analysis in

\footnotetext{
${ }^{*}$ Corresponding author.

E-mail: arijita@barc.gov.in

Tel: +912225590630
}

\section{ABSTRACT}

A D.C. arc carrier distillation atomic emission spectrometrybased analytical method was developed for the determination of 20 metallic impurities at the trace level. A suitable composition of the carrier gas ( $5 \% \mathrm{AgCl})$ was optimized to sweep away the trace metallic constituents into the arc, leaving the refractory nuclear material matrix inside the electrode to avoid spectral interference from the emission-rich major matrix. The method was optimized by using a suitable choice of interference-free analytical lines for the trace elements with desired analytical performance, including detection limts, linear dynamic range, and sensitivity. The method was validated using synthetic samples analyzed against $\mathrm{U}_{3} \mathrm{O}_{8}$ standards as well as $30 \% \mathrm{PuO}_{2}$ mixed oxide standards Using the optimized methods, actual U-Pu-Zr alloy samples were analyzed, and the method was found to be satisfactory.

spite of its poor precision compared to ICP-AES.

In a three-stage Indian nuclear energy program, plutonium has been used in the $2^{\text {nd }}$ stage, mainly for breeding purposes (15-16). The fissile isotope of ${ }^{239} \mathrm{Pu}$ is being generated from the fertile ${ }^{238} \mathrm{U}$. According to the breeding concept, the breeding ratio and the doubling time are very important. Higher breeding ratios and lower doubling times are the desirable situation. Low light atom density in the fuel materials can induce a higher breeding ratio. The oxide fuel has a very low breeding ratio $(1: 1)$, followed by nitride and carbide, whereas the alloy fuel has the highest breeding ratio and low doubling time. Hence, alloy fuel is considered to be one of the most advanced fuels in the world senario and U-Pu-Zr is one of such important fuel material investigated in the present study (17-18). The extent of $\mathrm{Zr}$ content in the alloys plays a significant role in the metallurgical, thermal, and physico-chemical properties of the alloy. A reduction in $\mathrm{Zr}$ content was found to decrease the liquid as well as the solid temperature of the alloy (19). By subjecting to the thermal cycles through phase transformation, the extruded rod of this alloy experiences an anisotropic growth and reduction in density (19-20).

Apart from the major constituents, the presence of trace metallic impurities plays a detrimental role in fuel performance. The elements $\mathrm{B}, \mathrm{Cd}$, and rare earths (Eu, Sm, Gd, Dy) have very low specification limits to maintain neutron economy for the fuel to sustain a fission reaction. The low melting analytes like $\mathrm{Zn}$ can result in liquidmetal embrittlement, while the high melting analytes such as W can cause creep resistance (21). As a whole, low light atom density is desirable to achieve expected burnup of the fuel material during its life time in the reactor. In view of these points, the present investigation deals with the development of a D.C. arc AES technique for the determination of 20 analytes at trace levels in a U-Pu-Zr matrix. 


\section{EXPERIMENTAL}

Instrumentation

A glovebox adapted Jarrell-Ash Mark III Atom Comp multi-channel direct reading spectrometer, equipped with D.C. arc and inductively coupled argon plasma excitation sources (Jarrell-Ash, USA), served as the basic experimental facility for the D.C. arc carrier distillation method for trace metal characterization of the U-Pu-Zr matrix. The instrumental parameters are listed in Table I, and the metal halides are grouped based on the volatility characteristics. Some of the volatile analytes can come to the arc instantaneously, while some need time to appear. The pre-burn step was taken to stabilize the arc which also optimizes arc wandering to achieve better precision of the replicate measurements.

\section{Reagents and Standards}

Specpure ${ }^{\circledR}$ grade (Alfa Aesar, USA) metal oxides and $\mathrm{AgCl}$ used in the present study were procured from SPEX Industries (Metuchen, NJ, USA). High purity $\mathrm{UO}_{2}$ and $\mathrm{PuO}_{2}$ powder, obtained by interlaboratory comparison experiments from different laboratories of the Department of Atomic Energy (DAE), Government of India, were used as the base materials for preparation of the standards.

\section{Method}

A standard carrier distillationtype electrode, ASTM designation E-130-66 type S-2 on a type S-1 pedestal, was used as the anode, whereas the pointed electrode, ASTM designation E-130-66 type $\mathrm{C}-1$, was used as the cathode. In carrier distillation, suitable carrier material was employed to sweep away the metallic impurities into the arc. 5\% $\mathrm{AgCl}$ was used as a carrier to form the volatile metal chlorides.
In the first step, all alloy samples were heated to $600{ }^{\circ} \mathrm{C}$ for 6 hours to convert the U-Pu-Zr samples into the most stable and refractory oxide form in order to avoid introduction of the emission-rich $\mathrm{U}$ and $\mathrm{Pu}$ into the arc. In the next step, the samples were mixed with a suitable composition of carrier and mixed in a pastel motor for half an hour. This step is required for complete homogenization of the samples with uniform and small particle size. The arc characteristic is highly influenced by the above parameters. In the next step, a suitable amount (100 $\mathrm{mg}$ ) of sample, called charge, was placed inside the

TABLE I

Optimization of Instrumental and Experimental Parameters

\begin{tabular}{|c|c|c|}
\hline D.C. Arc Current & \multicolumn{2}{|l|}{$12.5 \mathrm{~A}$} \\
\hline Sample Charge & \multicolumn{2}{|c|}{$100 \mathrm{mg}$ of $\mathrm{U}-\mathrm{Pu}-\mathrm{Zr}$ containing $5 \%$ carrier $(\mathrm{AgCl})$} \\
\hline Arc Gap & \multicolumn{2}{|c|}{$4 \mathrm{~mm}$ (constant throughout the exposure period) } \\
\hline Position & \multicolumn{2}{|c|}{ Symmetric with respect to entrance slit } \\
\hline Slit Height & \multicolumn{2}{|l|}{$3 \mathrm{~mm}$} \\
\hline Slit Width & \multicolumn{2}{|l|}{$25 \mu \mathrm{m}$} \\
\hline $\begin{array}{c}\text { Exposure Time } \\
\text { Elements }\end{array}$ & $\begin{array}{l}\text { Pre-burn } \\
\text { (s) }\end{array}$ & $\begin{array}{c}\text { Exposure } \\
\text { (s) }\end{array}$ \\
\hline $\mathrm{Cr}$ & 5 & 35 \\
\hline $\mathrm{Cu}$ & 5 & 35 \\
\hline $\mathrm{Fe}$ & 5 & 35 \\
\hline $\mathrm{Ni}$ & 5 & 35 \\
\hline $\mathrm{Mg}$ & 5 & 35 \\
\hline $\mathrm{Zn}$ & 5 & 35 \\
\hline Mo & 5 & 35 \\
\hline $\mathrm{Pb}$ & 5 & 35 \\
\hline W & 5 & 35 \\
\hline $\mathrm{Al}$ & 10 & 30 \\
\hline B & 3 & 20 \\
\hline Sn & 3 & 20 \\
\hline V & 8 & 35 \\
\hline $\mathrm{Cd}$ & 2 & 15 \\
\hline $\mathrm{Ca}$ & 5 & 30 \\
\hline $\mathrm{Be}$ & 5 & 25 \\
\hline Co & 5 & 25 \\
\hline Mn & 5 & 25 \\
\hline $\mathrm{Si}$ & 5 & 25 \\
\hline $\mathrm{Na}$ & 5 & 25 \\
\hline
\end{tabular}




\section{Atomic Spectroscopy \\ 1 Vol. 40(6), Nov./Dec. 2019}

anode. Four charges were prepared to have replicate measurements for each sample and arced for their analysis.

Since the present matrix is new (matching standards were not available), a set of two standards, 35\% $\mathrm{Pu}$ MOX standard and $\mathrm{U}_{3} \mathrm{O}_{8}$ standard, was used and their performance results compared. A sevenpoint standarization technique was used to establish the calibration curves. Depending on the specification limits of the analytes, the standards were of different concentration ranges. Table II lists the concentration range of the different analytes used in the standard for establishing the linear dynamic range in the calibration curves.

\section{RESULTS AND DISCUSSION}

Figure 1 shows a typical arrangement of the sample introduction system in D.C. arc carrier distillation. A suitable amount of sample charge was put in the anode, while the cathode is pointing to the top of the anode maintaining an arc gap equal to $4 \mathrm{~mm}$. Maintaining this arc gap is very important in order to strike the arc and to get correct signal intensity. The anode is fitted into a pedestal which is attached to the sample introduction system, so that the arc heat generated is distributed homogeneously throughout the sample charge in the electrode. Befor arcing, the samples need to be tapped and vented. Tapping avoids the physical introduction of the sample on impact of the electron coming from the cathode during arc formation and also the homogeneous distribution of the charge in the electrode. On the other hand, venting allows the easy evolution of gases into the arc without physically dragging the sample into the arc. The cathode is kept pointed to ensure that the electrons directed towards the cup of the anode are making an impact with the sample, resulting in excitation

TABLE II

Concentration Range (mg/g) for Analytes in the Standards

\begin{tabular}{lccccccc}
\hline Element & Std 1 & Std 2 & Std 3 & Std 4 & Std 5 & Std 6 & Std 7 \\
\hline $\mathrm{B}, \mathrm{Be}$ & 0.1 & 0.2 & 0.5 & 1.0 & 2.0 & 5.0 & 10 \\
$\mathrm{Sn}$ & 1 & 2 & 5 & 10 & 20 & 50 & 100 \\
$\mathrm{Mn}, \mathrm{Na}, \mathrm{Cu}$ & 2 & 4 & 10 & 20 & 40 & 100 & 200 \\
$\mathrm{Co}, \mathrm{Cr}, \mathrm{Mg}$, & & & & & & & \\
$\mathrm{Ni}, \mathrm{V}, \mathrm{Ca}, \mathrm{Pb}$ & 5 & 10 & 25 & 50 & 100 & 250 & 500 \\
$\mathrm{Fe}, \mathrm{Zn}, \mathrm{Al}, \mathrm{Mo}$ & 10 & 20 & 50 & 100 & 200 & 500 & 1000 \\
$\mathrm{~W}$ & 40 & 80 & 200 & 400 & 800 & 2000 & 4000 \\
$\mathrm{Si}$ & 80 & 120 & 240 & 440 & 840 & 2040 & 4040 \\
\hline
\end{tabular}

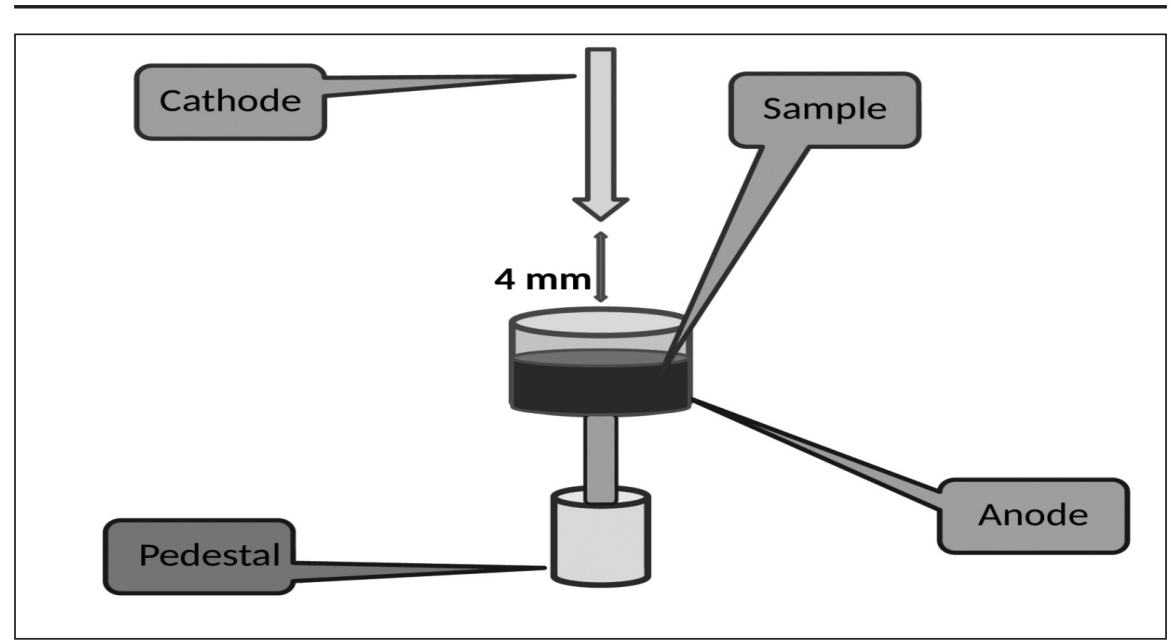

Fig. 1. Sample introduction arrangement in D.C. arc.carrier distillation technique.

and emission. This pointed electrode also helps to reduce arc wandering, which is one of the major reasons of poor precision. Unlike a plasma source, the D.C. arc source is not optically thin in nature. This means that the temperature of the central zone of the arc was found to be higher compared to the outer sphere. Therefore, there is a chance of self-absorption, which may have a detrimental effect on the linear dynamic range of the analytical lines.

Most of the emission lines found in the spectra of D.C. arc atomic emission spectrometry are atomic in nature. The temperature of the central zone of the arc was found to be $3000 \mathrm{~K}$, which is much lower than that of the plasma $(6500 \mathrm{~K})$; therefore, in D.C. arc the number of lines available for estimation is comparatively less. Even though this would lead to less choice of analytical lines, this fact ultimately may lead to less spectral interference as compared to an inductively coupled plasma source. In view of these points, suitable interferencefree analytical lines for these 20 trace metallic constituents were identified and their analytical performance, including sensitivity, detection limit, and linear dynamic range, are summarized in Table III. The detection limits were evaluated based on the concentration corresponding to the intensity equivalent to three times the standard deviation of the blank values. The 
TABLE III

Performance of Analytical

Lines Chosen for the

Determination of Impurities

\begin{tabular}{lclc}
\hline $\begin{array}{l}\text { Ele- } \\
\text { ments }\end{array}$ & $\begin{array}{c}\text { Analytical } \\
\text { Line } \\
(\mathrm{nm})\end{array}$ & $\begin{array}{l}\text { Det. } \\
\text { Limit } \\
(\mathrm{ppm})\end{array}$ & $\begin{array}{c}\text { Sensi- } \\
\text { tivity } \\
\text { (counts/ } \\
\text { ppm) }\end{array}$ \\
\hline $\mathrm{Al}$ & 308.2 & 10 & 75 \\
$\mathrm{~B}$ & 249.7 & 0.1 & 150 \\
$\mathrm{Be}$ & 234.8 & 0.1 & 95 \\
$\mathrm{Ca}$ & 396.8 & 5 & 110 \\
$\mathrm{Cd}$ & 228.8 & 0.1 & 120 \\
$\mathrm{Co}$ & 242.4 & 5 & 58 \\
$\mathrm{Cr}$ & 357.8 & 5 & 69 \\
$\mathrm{Cu}$ & 324.7 & 2 & 77 \\
$\mathrm{Fe}$ & 259.9 & 10 & 89 \\
$\mathrm{Mg}$ & 285.2 & 5 & 62 \\
$\mathrm{Mn}$ & 257.6 & 2 & 54 \\
$\mathrm{Mo}$ & 202.0 & 10 & 44 \\
$\mathrm{Na}$ & 588.9 & 2 & 48 \\
$\mathrm{Ni}$ & 305.0 & 5 & 81 \\
$\mathrm{~Pb}$ & 283.3 & 5 & 59 \\
$\mathrm{Si}$ & 288.1 & 80 & 37 \\
$\mathrm{Sn}$ & 242.1 & 1 & 78 \\
$\mathrm{~V}$ & 318.5 & 5 & 55 \\
$\mathrm{~W}$ & 239.7 & 40 & 42 \\
$\mathrm{Zn}$ & 213.8 & 10 & 66 \\
\hline
\end{tabular}

sensitivities were evaluated as the slope of the calibration curves for that particular emission line or the intensity per unit concentration of the analytes.

A set of synthetic samples was prepared and analyzed against the $\mathrm{U}_{3} \mathrm{O}_{8}$ standards as well as the $35 \%$ $\mathrm{PuO}_{2}$ standards in order to validate the optimized methodology (see Table IV for the analytical results). As for for the preparation of the standards, a similar methodology was adopted for making the synthetic samples. Depending on the specified concentration of the metal ion, equivalent amounts of metal oxides were added to the Specpure $\mathrm{U}_{3} \mathrm{O}_{8}$ base material. Then this mixture was ground well for complete homogenization and

TABLE IV

Analytical Results for Synthetic Samples Arced Against $\mathrm{U}_{3} \mathrm{O}_{8}$ Standards and 35\% $\mathrm{PuO}_{2}-\mathrm{U}_{3} \mathrm{O}_{8}$ Mixed Oxide Standards

\begin{tabular}{|c|c|c|c|c|c|c|}
\hline \multirow[b]{2}{*}{$\begin{array}{l}\text { Ele- } \\
\text { ment }\end{array}$} & \multicolumn{3}{|c|}{ Synthetic Sample 1} & \multicolumn{3}{|c|}{ Synthetic Sample 2} \\
\hline & $\begin{array}{l}\text { Amount } \\
\text { Added }\end{array}$ & $\begin{array}{l}\text { Amount } \\
\text { Estimated } \\
\text { Against 35\% } \\
\mathrm{PuO}_{2} \text { Stds. }\end{array}$ & $\begin{array}{c}\text { Amount } \\
\text { Estimated } \\
\text { Against } \\
\mathrm{U}_{3} \mathrm{O}_{8} \text { Stds. }\end{array}$ & $\begin{array}{l}\text { Amount } \\
\text { Added }\end{array}$ & $\begin{array}{l}\text { Amount } \\
\text { Estimated } \\
\text { Against 35\% } \\
\mathrm{PuO}_{2} \text { Stds. }\end{array}$ & $\begin{array}{c}\text { Amount } \\
\text { Estimated } \\
0 \quad \text { Against } \\
\mathrm{U}_{3} \mathrm{O}_{8} \text { Stds. }\end{array}$ \\
\hline Al & 25 & $23 \pm 5$ & $26 \pm 4$ & 500 & $460 \pm 50$ & $510 \pm 30$ \\
\hline B & 0.3 & $0.26 \pm 0.05$ & $0.25 \pm 0.06$ & 2 & $1.8 \pm 0.4$ & $2.3 \pm 0.4$ \\
\hline $\mathrm{Be}$ & 2 & $2.2 \pm 0.5$ & $1.9 \pm 0.5$ & 10 & $11 \pm 4$ & $8 \pm 3$ \\
\hline $\mathrm{Ca}$ & 50 & $48 \pm 6$ & $47 \pm 5$ & 100 & $96 \pm 10$ & $110 \pm 20$ \\
\hline $\mathrm{Cd}$ & 0.2 & $0.22 \pm 0.06$ & $0.21 \pm 0.03$ & 1 & $0.9 \pm 0.2$ & $1.2 \pm 0.2$ \\
\hline $\mathrm{Co}$ & 20 & $21 \pm 5$ & $19 \pm 4$ & 200 & $220 \pm 40$ & $210 \pm 40$ \\
\hline $\mathrm{Cr}$ & 15 & $15 \pm 4$ & $17 \pm 6$ & 300 & $290 \pm 30$ & $260 \pm 50$ \\
\hline $\mathrm{Cu}$ & 10 & $10 \pm 2$ & $12 \pm 4$ & 100 & $90 \pm 20$ & $105 \pm 25$ \\
\hline $\mathrm{Fe}$ & 100 & $90 \pm 8$ & $95 \pm 8$ & 1000 & $980 \pm 90$ & $1010 \pm 60$ \\
\hline Mg & 10 & $10 \pm 4$ & $12 \pm 3$ & 50 & $48 \pm 6$ & $49 \pm 7$ \\
\hline Mn & 10 & $8 \pm 1$ & $9 \pm 2$ & 200 & $196 \pm 11$ & $193 \pm 9$ \\
\hline Mo & 2 & $2 \pm 0.2$ & $1.8 \pm 0.5$ & 200 & $180 \pm 20$ & $210 \pm 20$ \\
\hline $\mathrm{Na}$ & 10 & $8 \pm 1$ & $10 \pm 2$ & 100 & $97 \pm 9$ & $101 \pm 11$ \\
\hline $\mathrm{Ni}$ & 20 & $18 \pm 3$ & $21 \pm 4$ & 500 & $480 \pm 40$ & $490 \pm 50$ \\
\hline $\mathrm{Pb}$ & 10 & $10 \pm 3$ & $8 \pm 2$ & 200 & $220 \pm 30$ & $190 \pm 30$ \\
\hline $\mathrm{Si}$ & 100 & $96 \pm 8$ & $105 \pm 11$ & 500 & $500 \pm 40$ & $520 \pm 30$ \\
\hline $\mathrm{Sn}$ & 5 & $5.3 \pm 0.7$ & $4.8 \pm 0.6$ & 10 & $9.5 \pm 0.8$ & $10.0 \pm 0.9$ \\
\hline V & 50 & $52 \pm 6$ & $45 \pm 8$ & 100 & $90 \pm 10$ & $110 \pm 10$ \\
\hline W & 100 & $109 \pm 12$ & $90 \pm 8$ & 200 & $180 \pm 20$ & $190 \pm 30$ \\
\hline $\mathrm{Zn}$ & 100 & $90 \pm 10$ & $97 \pm 8$ & 100 & $100 \pm 10$ & $100 \pm 9$ \\
\hline
\end{tabular}

hence, the synthetic samples were ready for analyses. The results revealed that the optimized method is successful in determining the analytes even at the specification limits.

Unlike plasma, the arc is a discreet phenomenon, i.e., each arc will have different characteristics. This would add to the poor precision of D.C. arc carrier distillation and the problem of arc wandering. However, the relative standard deviation was found to be less than $20 \%$. Two synthetic samples were preapared by adding a suitable amount of analyte metal oxides from the master impurity mixtures. The analyte concentration was chosen in such a way that with the developed methodology it is possi- ble to analyze the metallic impurities at the specification limits provided by the fuel designer for the $\mathrm{UO}_{2}$ matrix and the $(\mathrm{U}, 35 \% \mathrm{Pu}) \mathrm{O}_{2}$ matrix, respectively. The data in Table IV show that the proposed method is very successful in determining the said 20 metallic constituents at the trace level using solid sampling. In addition, it saves a great deal of time in comparison to the process of dissolution of the samples, followed by the ability of chemical separation of the major matrix, i.e., $\mathrm{U}$ and $\mathrm{Pu}$, and also avoids the chances of cross-contamination during the different stages of sample preparation. Figure 2 shows the calibration curves for $\mathrm{B}$, Be, Sn, and W.

Table V summarizes the results 


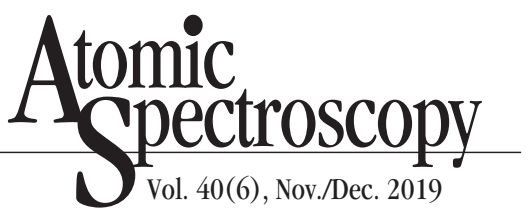

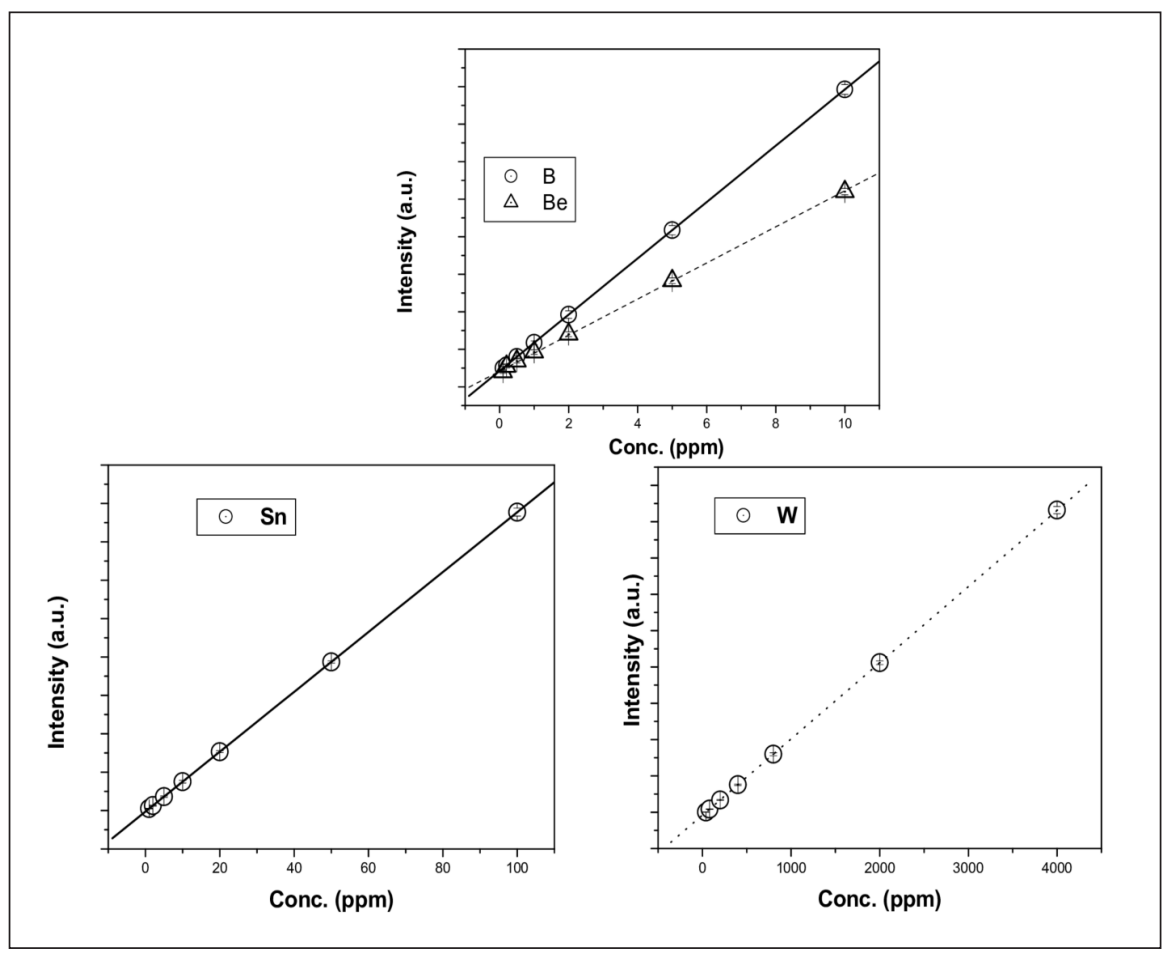

Fig. 2. Typical calibration curves for $B, B e, S n$, and $W$.

obtained by the analysis of actual (U-Pu-Zr) alloy samples arced against both the standards as previously specified. Both data were found to be in good agreement. The elements $\mathrm{B}, \mathrm{Be}$, and $\mathrm{Cd}$ were found to be less than $0.2 \mathrm{ppm}$; $\mathrm{Ca}$, $\mathrm{Cu}, \mathrm{Mn}, \mathrm{Na}, \mathrm{Ni}, \mathrm{Pb}$, and $\mathrm{Sn}$ in the range of 1-10 ppm; $\mathrm{Zn}, \mathrm{W}, \mathrm{V}, \mathrm{Si}$, $\mathrm{Mo}, \mathrm{Mg}$, and $\mathrm{Co}$ in the range of 10-20 ppm, while Fe and Cr were found to be above $20 \mathrm{ppm}$. The source of this increase might be the $\mathrm{Fe}$ and $\mathrm{Cr}$ of the stainless steel container used for fabrication of the fuel pins. It should also be noted that the rare earth elements $\mathrm{Eu}, \mathrm{Sm}$, $\mathrm{Gd}$, and Dy have very stringent specification limits for nuclear materials and, as a result, their analysis by using the D.C. arc carrier distillation AES technique is not suitable. These rare earth elements form refractory oxides like the nuclear materials, therefore, correct sweeping of the arc is not possible to achieve the low specification provided by the fuel designer.

\section{CONCLUSION}

As part of the chemical quality control and quality assurance strategy, a D.C. arc carrier distillation atomic emission spectrometry method was developed for the determination of the common metallic impurities of $\mathrm{Al}, \mathrm{B}, \mathrm{Be}, \mathrm{Ca}$, $\mathrm{Cd}, \mathrm{Co}, \mathrm{Cr}, \mathrm{Cu}, \mathrm{Fe}, \mathrm{Mg}, \mathrm{Mn}, \mathrm{Mo}, \mathrm{Na}$, $\mathrm{Ni}, \mathrm{Pb}, \mathrm{Si}, \mathrm{Sn}, \mathrm{V}, \mathrm{W}$, and $\mathrm{Zn}$. Instead of chemical separation, the analytes were physically separated from the major matrix based on the volatility difference between the analytes and the major matrix by using a suitable composition of carrier ( $5 \% \mathrm{AgCl})$ to avoid spectral interferences. The seven-point stadardization using $\mathrm{U}_{3} \mathrm{O}_{8}$ standards as well as the $30 \% \mathrm{PuO}_{2}$ mixed oxide standards to establish the calibration curves were found to be effective for their determination at the trace level. The results of the proposed method are in good agreement as validated by a synthetic sample analysis and the analysis of an actual (U-Pu-Zr) sample.
TABLE V

Comparison of Analytical Results in (U-Pu-Zr) of an Actual Alloy in ppm in the Sample Using Two Sets of Standards

\begin{tabular}{ccc}
\hline $\begin{array}{c}\text { Ele- } \\
\text { ments }\end{array}$ & $\begin{array}{c}\text { Method A } \\
\text { (with 35\% } \\
\mathrm{PuO}_{2} \text { stds.) }\end{array}$ & $\begin{array}{c}\text { Method B } \\
\text { (with } \mathrm{U}_{3} \mathrm{O}_{8} \\
\text { stds.) }\end{array}$ \\
\hline $\mathrm{Al}$ & $15 \pm 2$ & $12 \pm 2$ \\
$\mathrm{~B}$ & $0.15 \pm 0.01$ & $0.18 \pm 0.02$ \\
$\mathrm{Be}$ & $0.12 \pm 0.01$ & $0.15 \pm 0.02$ \\
$\mathrm{Ca}$ & $10 \pm 2$ & $10 \pm 3$ \\
$\mathrm{Cd}$ & $0.10 \pm 0.009$ & $0.15 \pm 0.02$ \\
$\mathrm{Co}$ & $14 \pm 3$ & $10 \pm 2$ \\
$\mathrm{Cr}$ & $22 \pm 4$ & $20 \pm 3$ \\
$\mathrm{Cu}$ & $5.0 \pm 0.9$ & $8 \pm 1$ \\
$\mathrm{Fe}$ & $25 \pm 4$ & $30 \pm 5$ \\
$\mathrm{Mg}$ & $17 \pm 2$ & $13 \pm 2$ \\
$\mathrm{Mn}$ & $8 \pm 2$ & $10 \pm 2$ \\
$\mathrm{Mo}$ & $11 \pm 2$ & $8 \pm 1$ \\
$\mathrm{Na}$ & $4.0 \pm 0.5$ & $6.1 \pm 0.6$ \\
$\mathrm{Ni}$ & $10 \pm 1$ & $12 \pm 1$ \\
$\mathrm{~Pb}$ & $5.0 \pm 0.8$ & $6.0 \pm 0.9$ \\
$\mathrm{Si}$ & $20 \pm 3$ & $18 \pm 4$ \\
$\mathrm{Sn}$ & $4.0 \pm 0.7$ & $5.0 \pm 0.7$ \\
$\mathrm{~V}$ & $12 \pm 2$ & $15 \pm 2$ \\
$\mathrm{~W}$ & $15 \pm 2$ & $15 \pm 4$ \\
$\mathrm{Zn}$ & $20 \pm 5$ & $12 \pm 4$ \\
\hline & &
\end{tabular}

$\overline{\text { Received August 20, } 2019}$.

\section{REFERENCES}

1. T. Shinonaga, D. Donohue, $\mathrm{H}$. Aigner, S. Bürger, D.Klose, T. Kärkelä, R. Zilliacus, A. Auvinen, O. Marie, and F. Pointurier, Anal. Chem. 84(6), 2638 (2012).

2. S. Bürgera, S. D. Balsleya, S. Baumanna, J. Bergera, S. F. Boulyga, J. A. Cunninghama, S. Kappel, A. Koepf, and J. Poths, Int. J. Mass Spec. 311, 40 (2012).

3. C. Testa, D. Desideri, M. A.Meli, and C. Roselli, J. Radioanal. Nucl. Chem. 194(1), 141 (1995).

4. F. X. Han, W. D. Patterson,Y. Xia, B. B. M. Sridhar, and Y. Su, Radioanal. Nucl. Chem.170(1-4), 161 (2006). 
5. M. Gopalkrishnan, K. Radhakrishnan, P.S. Dhami, V.T. Kulkarni, M.V. Joshi, A.B. Patwardhan, and J.N. Mathur, Talanta 44(2), 169 (1997) .

6. R. Ko, Appl. Spectrosc. 38(6), 909 (1984).

7. C. Mahan, S. Bonchin, D. Figg, D. Gcrth, and C. Collier, J. Anal. At. Spectrom. 15(8), 929 (2000).

8. A.G. Page, K.H. Madraswala, S.V. Godbole, M.J. Kulkarni, V.S. Mallapurkar, and B.D. Joshi, Fresenius' Zeitschrift für analytische Chemie 315(1), 38 (1983).

9. A. Sengupta, V.C. Adya, T.K. Seshagiri, S.K. Thulasidas, S.V. Godbole, and V. Natarajan, J. Res. Spec., DOI: 10.5171/2014.757111(2014)

10. N. Pathak, V.C. Adya, S.K. Thulasidas, A. Sengupta, T.K. Seshagiri, and S.V. Godbole, At. Spectrosc. 35(1), 17 (2014).

11. A. Sengupta, V.C. Adya, and S.V. Godbole, J. Radioanal. Nucl. Chem. 298(2), 1117 (2013).

12. A. Sengupta, V.C. Adya, M. Kumar, S.K. Thulasidas, S.V. Godbole, and V.K. Manchanda, At. Spectrosc. 32(2), 49 (2011).

13. A. Sengupta and V.C. Adya, At. Spectrosc. 34(6), 207 (2013).

14. A. Sengupta, Y. Airan, S.K. Thulasidas, and V. Natarajan, At. Spectrosc. 37(2), 61 (2016)

15. H. Eccles, Solvt. Extr. Ion Exch. 18(4), 633 (2000).

16. J.N. Wilson, A. Bidaud, N. Capellan, R. Chambon, S. David, P. Guillemin, E. Ivanov, A. Nuttin, and O. Meplan, Annals Nucl. Energy 36(3), 404 (2009).

17. K. Kinoshita, T. Koyama, T. Inouea, M. Ougier, and J-P. Glatz, J. Phys. Chem. Solids 66(2-4), 619 (2005).

18. Y.S. Kim, G.L. Hofman, S.L. Hayes, and Y.H. Sohn, J. Nucl. Mater. 327(1), 27 (2004).

19. Y.H. Sohn, M.A. Dayananda, G.L. Hofman, R.V. Strain, and S.L. Hayes, J. Nucl. Mater. 279(2-3), 317 (2000).

20. M. Iizuk, K. Kinoshit, and T. Koyam, J. Phys. Chem. Solids 66
(2-4), 427 (2005).

21. A. Sengupta, V.C. Adya, and S.V. Godbole, J. Radioanal. Nucl. Chem. 292(3), 1259 (2012). 